\title{
Adam Wieczorek
}

Faculty of Economics, University of Warmia and Mazury, Poland

\section{LOGISTICS IN RACING SPORTS ON THE EXAMPLE OF F1}

\begin{abstract}
Logistics operations are an inseparable part of every process that humans can conduct. No major process could proceed in a right way without logistics. In the case of every sport, and in the case of racing sports in particular, providing the right resources not only enables the race to take place but may be decisive about the potential results of each team as well. F1, which is called the "Queen" of motor sports, a main process in this case, has an essential need for logistics services. Considering this case, the purpose of this paper was to present the extent of logistics services within $\mathrm{F} 1$ as a good example of operation of logistics processes. The work is a review, basing mainly on various examples and practices from the 2018 season. The writing of this article was supported mainly by foreign internet sources, along with domestic literature and the author's own observations on the functionality of $\mathrm{F} 1$ races and the tasks of logistics processes.
\end{abstract}

Keywords: logistics, racing, F1, transport

JEL: R490

\section{Introduction}

The F1 races are recognized as the highest level of car racing. Year to year there are more and more people which are interested in this form of sport. In addition, this racing sport type is constantly developed and upgraded, and many changes have been introduced thereto over the years since the first Grand Prix (GP). The races take place in various countries and on various continents. In addition to the racing drivers, every weekend each racing event is served by professional mechanics and many other people taking care that the races should run smoothly, safely and properly. Moreover, this great interest is the reason why fans and reporters 
more and more often visit racing venues for a "live" experience. The entire F1 functionality involves much service which has to be provided by logistics. Providing all the necessary resources in accordance with the $5 \mathrm{R}$ rule is quite a big challenge for people who are planning all the operations but also for those who are personally responsible for their performance. In this respect, the aim of this paper is to show, on examples, how logistics services are provided according to the $5 \mathrm{R}$ rule. Formula 1 is a significant example of how important serving the main process is and the fact that such process would not be possible without logistics. The article has the nature of a review based mainly on foreign sources of information, along with the domestic literature and the author's own observations.

\section{Logistics service}

Every action connected with conducting various processes requires appropriate resources. The same situation arises when it comes to racing, as it would not be possible without the proper factors. To put in the simplest way, it is possible to indicate that logistics services, in accordance with the $5 \mathrm{R}$ rule, are a necessary component of every action with various types of sports which can be presented as the main process (Chaberek, Mańkowski, 2017). Referring to these requirements for the purpose of this article, providing adequate resources according to the $5 \mathrm{R}$ rule will enable the proper way of dealing with the F1 Grand Prix during one weekend. Logistics operations must be performed at the highest level due to the requirements of the main process constituted by the GP every weekend. Determining the appropriate resources in the appropriate quantity, delivering them at the correct time to the right place at the right cost, conditions the success or lack thereof during a main process which is F1 GP (Chaberek, 2014). On the basis of such statements it is possible to define how big a challenge the logistics service of F1 racing is. In addition, it is worth mentioning that the requirements for the needed resources have been increasing for almost over 70 years now (the first F1 race was staged in 1950). F1 is an interesting example of how proper logistics services should look like. Such an example is good because of the various requirements and the short periods of time for making the necessary decisions. Both processes: the main process and logistics are connected with each other and cannot proceed separately. The main process determines all the requirements which must be met by logistics processes. Due to this fact the F1 races are an important source of a "job well done". The 2018 season races were organized in 21 countries on 5 continents, and there was no situation when one of the 5Rs was not fulfilled, as such situation would have caused serious losses, both for the teams but also for sponsors and fans, and it is therefore that logistics operations within F1 are of such importance. 


\section{F1 logistics in practice}

Access to this specific sport is highly limited and only the best drivers around the world may participate in races. Since 1950 races have been staged around the whole world attracting crowds of tourists. However, for this to be possible, thousands of people must do their jobs properly to enable the functioning of the weekend's Grand Prix. The GP is organized every year, starting from February, ending in December. The tour is staged in 21 countries on the 5 continents, which in itself is a logistics challenge (Formula $1^{\circledR}$. The Race Behind the Race..., 2018). While drivers and teams are competing between themselves, the main part of the logistics service rests with the official operators such as, for example, DHL, that needs to deliver the required "equipment" and supervise all the necessary components for the race preparations and progress, so that they should be at the right place at the right time. Their operations are the essence of the $5 \mathrm{R}$ rule of logistics.

2018 F1 championship was staged in 21 various countries, and it was really a special year for Formula 1, as it was for the first time in history that the GP was held three weekends in a row, what was an enormous challenge for the logistics operators. Each racing weekend consisted of three days of competition (Friday, Saturday, Sunday), but the special "racing town", garages and service had to be ready and operational no later than on Thursday before the race. In 2018 there were ten teams represented by two drivers each (F1 Racing Teams 2020 .., 2018). The statistics for the 2018 year are highly impressive, as far as the required resources (goods) needed for transport in a nine-month period only are considered. The average weight of cargo necessary to be transported between every race is about 2000 tonnes of which 600 tonnes was transported via air transport and 1000 tonnes via maritime transport (the remaining cargo was transported by trucks). Boeing 747 planes flew around 132000 kilometres during one racing season. It has been measured that there are about 40-50 tonnes of cargo on average for one team. And these are the resources for the racing only. DHL which is a long-time partner delivers also other resources for broadcasting and hotel services. It has been also measured that over 150000 of additional broadcasting equipment, 30 hotel service containers and about $10000 \mathrm{~kg}$ of electronic devices for every team were transported in 2018 (Formula $1^{\circledR}$. The Race Behind the Race..., 2018). Numerical statistics show how much effort must be put into logistics services to deliver the right resources for Formula 1. The presented statistics are limited only to the "technical" requirements of teams. In addition, it is necessary to "deliver" people, arrange booking the accommodation, where one team may need more than 100 hotel beds. Furthermore, special vehicles and machines which will be used in team villages and in the paddock area need to be provided. The technological development has also affected the main process which is the race itself. In such case there is also the requirement for special IT services whereby the right resources are also demanded (Formula $1^{\circledR}$. The Race Behind the Race..., 2018). It is a crucial point, as appropriate telemetric data allows making strategic decisions which may determine the victory or loss, however, in such situation, logistics is also responsible for the appropriate resources such as telemetric data which may contribute to the winning of the driver or the team. Other limitations and challenges concerning the logistics service may result from 
political issues and country-specific requirements. The first race during the 2018 season which was held in Australia can be used as an example here. The motorhome and the racing circuit are located in a park, which imposes additional needs on teams concerning potential pollution or damage to green areas. On the other hand, in China there are very stringent rules concerning hazardous goods and lithium batteries, which must be planned and accepted by the country long before the teams arrive (PCM_ADMIN, 2018).

The adequate resources for every team are transported using three modes of transport: road, air and sea. As long as weekend's races are staged in Europe, most of the equipment is transported by trucks on road. The situation is slightly more complicated when transport between continents is needed. Appropriate equipment, tools and devices (resources) are divided into two types - necessary and standard parts. The necessary parts have priority when it comes to air transport, while standard parts are divided into five sets which will be transported between two race locations. One set is sent to the first of four "away" races and the other three sets will be sent back to the headquarters of a team. As an example, it is shown that the set from Malaysia is sent directly to Canada, the set from Singapore is shipped to Brazil, and the set from Japan is sent to Abu Dhabi. The required sets for Russia or Austria are sent directly from the headquarters. These sets are usually transported by sea, what of course needs suitable planning and prior arrangement and division in what directions the resources will be sent to be delivered to the right place at the right time (Iyengar, 2017) (Table 1).

Table 1. Differences between using air and sea transport in the logistics of the Red Bull Racing F1 team

\begin{tabular}{|c|c|}
\hline Air transport & Maritime transport \\
\hline Sent 7-9 days before the race & Sent 4-6 weeks before race \\
\hline Renault sends engines, Pirelli sends tyres & $\begin{array}{l}\text { Usage of car transport to deliver the cargo } \\
\text { to the harbour and pit lanes }\end{array}$ \\
\hline Plane charter by Formula One Management & Significant savings compared to air transport \\
\hline- & $\begin{array}{l}\text { Used for transport of heavy items and items with } \\
\text { the shelf life of about } 4-5 \text { years }\end{array}$ \\
\hline \multicolumn{2}{|c|}{ Statistics } \\
\hline $\begin{array}{l}13 \text { specially designed containers with: } \\
\text { Electronics and IT systems } \\
2 \text { race cars } \\
\text { Spare chassis } \\
\text { Bodyworks } \\
40 \text { sets of wheels (without tyres) }\end{array}$ & $\begin{array}{l}5 \text { containers with: } \\
\text { All garage equipment } \\
\text { No sensitive parts } \\
\text { No car parts }\end{array}$ \\
\hline
\end{tabular}

Source: (own elaboration based on: Iyengar, 2017)

Each team "packs" its cars in specially designed containers in such a way as to maximize the usage of cargo space. As statistical data shows, it is possible to say that every team transports spare parts to be ready to prepare their vehicles, about 40 sets of tyres and wheels, 2500 litres of fuel, 200 litres of engine oil and about 90 litres of a cooling factor are shipped. These things need tools, computer hardware, IT and appropriate amounts of food for the whole team, which should 
be enough for preparation of 200 meals (including the tableware and cookware) (Davies, 2014). According to such statistics the biggest teams have about 50 tonnes of needed resources. In addition, the rising popularity of this sport is the reason why the needs for logistics services are rising proportionally to the needs for the right resources. Thus, we can say that teams which are responsible for logistics services of various teams, are also potentially responsible for the performance of drivers and the rest of the team on the track, and all of this owing to successful fulfilment of the $5 \mathrm{R}$ rule of logistics.

Another example of the actions carried out by logistics services on a racing weekend (main process) needs to be presented to get a fuller meaning of logistics and its responsibilities. The example will be a description of the logistics services provided by a logistics operator, Mercedes-AMG Petronas, after a race finished at the SPA circuit in Belgium in 2017. The official logistics partner of the Mercedes team is DB Schenker. The situation after the race was rather tense as the next race was just within a week and it was supposed to take place on the Monza circuit in Italy. When the press conferences were coming to an end, the first actions to disassembly the motorhome were taken. The crew started to pack the first items. The team consisted of 63 members and they had 18 heavy goods vehicles. Simultaneously to these activities, extra crews along with race engineers were disassembling carefully the cars. The prepared vehicles started their journey first thing in the morning on the next day (Monday) to another race track located about $1100 \mathrm{~km}$ away. The trucks which were carrying the parts of the motorhome and race cars are always of the latest type to ensure fluent and safe transport at the right time. The reliability of transport in this case is fully connected with the accomplishment of two aims, namely, the right place and the right time. During the night the whole motorhome was disassembled and loaded onto trucks which needed to arrive at the next track as first (Formula 1: poczatek..., n.d.). The vehicles with the necessary equipment had to get to the next track not later than on Thursday (before the racing on Friday), so that the crews could prepare the motorhome, equip the garages and assemble the race cars before Friday morning. Tasks in this field require a high level of planning and commitment of the whole crew. It is one of the key factors determining the success of teams and drivers. The Mercedes-AMG Petronas team won the best constructor title and their driver won the $5^{\text {th }}$ world F1 championship (in the 2018 season), and such achievements would not have been possible without the right resources provided with the 5Rs.

Another example of the relevance of actions in the field of logistics worth mentioning is the situation from 2018 when for the first time in the F1 history, races were staged during three straight weekends on various tracks in Europe, France, Austria and England (Young, 2018). It was an enormous challenge for every logistics operator, with the main focus on enterprises such as DB Schenker and DHL. They needed to cover over $4000 \mathrm{~km}$ with the equipment weighting about 20 tonnes per team. The works including the planning and setting of routes were commenced five days before the first race, which was to take place in France with the arrival of the first vehicles on the $19^{\text {th }}$ of June. On the next day the work of assembling garages for the teams was completed. Obviously the rest of the equipment would be gathered until Saturday night, so that, right before the race the team should 
have access to fresh parts and needed components. During the performance of last tasks in France, the first vehicles would start the route to the subsequent stages. Due to the short periods of time between the races, the teams were also using the air transport and some vehicles started the route directly to the venue of the third race which was to be held in England. On Saturday, the 23 $3^{\text {rd }}$ of July the first vehicles which had set out from the DHL base started arriving at the Red Bull track in Austria after travelling for almost $1480 \mathrm{~km}$ (despite the fact that the race in France had not started yet). Due to the previously mentioned tense plan each of the teams was using two various race sets. The sets which were transported by air would be used in Austria, and those from France would be moved to England next Tuesday (the $26^{\text {th }}$ of July). On Monday (the $25^{\text {th }}$ of July) the trucks would start to transport the motorhomes with the plan to unload them on the next day - with a distance of $1118 \mathrm{~km}$ to cover. Also on this day, the trucks with fuel would start their journey from the appropriate supply depots planning to arrive on Tuesday, the $26^{\text {th }}$ of July, as well. In addition, as of the $25^{\text {th }}$ of July the first works on the preparation of the pit lane and the paddock were gaining momentum. Tuesday, the $26^{\text {th }}$ of June brought new progress in the process of building the paddock in Austria, along with the arrival of the first trucks from France and supply bases in Europe. The remaining transport trucks from France were carrying garage equipment and supplies needed for the Pit Lane in England - the distance covered was about $1445 \mathrm{~km}$. The planned arrival date was Saturday (the $30^{\text {th }}$ of June). On Wednesday the paddock works were finished and the first drivers started to arrive. Saturday, the $30^{\text {th }}$ of June was the day on which the first works on the Silverstone (England) track started. On the $1^{\text {st }}$ of July (Sunday), immediately after the awards ceremony, the first vehicles with packed race cars and parts of the motorhome began their journey to England. During this journey the fuel trucks would join for the next race which was to be staged Great Britain. The distance between those two venues was $1587 \mathrm{~km}$. Additional challenges for the teams would be connected with various race car upgrades. This would result in a requisition for additional transport from factories based in England, Italy and Switzerland. On Tuesday (the $3^{\text {rd }}$ of July) the first vehicles from Austria arrived, and the work to build the motorhome and the paddock started and had to be completed by Thursday. On the $5^{\text {th }}$ July (Thursday) the racing village in Silverstone was open, and the last works before the practice session were coming to the end. The interesting fact here is that the teams and their resources were one thing, but parallel to this, a large number of reporters were also travelling the same way from France to England via Austria, which obviously required a proper approach to for planning and organization of logistics processes (Formula $1^{\circledR}$. DHL Ensures Smooth Logistics..., 2018). In this way, the first day of the last race of an unusual triple-header started. The operation which was carried out over a period of these three weeks proved once again the importance of logistics in the proper functioning of a main process which are the various Grand Prix weekend's races. Not even one of the described races would have taken place without the right resources. It shows once again the side of logistics which can be labelled as "good work" which also confirms the fact that no action is possible without logistics. 


\section{Conclusions}

Every activity, sport, process requires the right resources. The $5 \mathrm{R}$ rule has its "reflection" in our every activity every day. The five factors which are the source of the $5 \mathrm{R}$ rule may be subjectively considered as a simple thing. In such a case it is important to show an example, such as the functioning of the Formula 1 event. The first Grand Prix ever took place in 1950, and since that time, F1 has been the subject of numerous changes, each of which generating needs for new resources. Not a single race could be held without sufficient logistics facilities and planning. The logistics services are responsible for: building the motorhomes on time, having the right equipment for mechanics, and ensuring that drivers have the right racing cars. The outcome of various races depends mostly on the driver's skills, the efficiency of his mechanics, the whole team, and of course, the car itself. At the same time, the extremely important logistics operations should not be forgotten, or what would be even worse, skipped. The fact that some of these operations are invisible to spectators does not mean that they do not exist. One can say that without proper logistics the Mercedes team and their drivers would not have won the constructor championships five times, and their driver would not have won the fifth world champion title, if it had not been for the logistics operations carried out in a proper way according to the $5 \mathrm{R}$ rule.

\section{References}

Chaberek, M. (2014), Theoretical, Regulatory and Practical Implications of Logistics. Log Forum, (10)1, pp. 3-10.

Chaberek, M., Mańkowski, C. (2017), Teleological Assumptions in the Process of Identification and Evaluation of Best Logistics Practices. Research Journal of University of Gdańsk, Transport Economics and Logistics, 71, pp. 7-8.

Davies, A. (2014), This Is How You Ship an F1 Car Across the Globe in 36 Hours, https://www. wired.com/2014/11/ship-f1-car-across-globe-36-hours/ [Accessed 26 November 2018].

F1 Racing Teams 2020 - Ferrari, McLaren, Mercedes and More (n.d.), https://www.formula1.com/ en/teams.html [Accessed 26 November 2018].

F1 ${ }^{\circledR}$, https://www.formula1.com/en/championship/inside-f1/understanding-f1-racing/ Logistics.html [Accessed 26 November 2018].

Formuła 1: początek logistycznych przygotowań do sezonu 2018 (n.d.), https://roadstars. mercedes-benz.com/pl_PL/magazine/transport/01-2018/formula-1-the-logistics-for-the2018-season-are-starting.html [Accessed 26 November 2018].

Formula $1^{\circledR}$. Enabling the Greatest Racing Spectacle on the Planet (n.d.), http://www.dhl.com/ en/about_us/partnerships/motorsports/formula_1.html [Accessed 26 November 2018].

Formula $1^{\circledR}$. DHL Ensures Smooth Logistics for the First Triple-Header in Formula 1 History (2018), https://www.dhl-in-motion.com/en/formula-1/article/dhl-ensures-smooth-logistics-for -the-first-triple-header-in-formula-1-history [Accessed 26 November 2018].

Formula $1^{\circledR}$. The Race Behind the Race: About Planning, Agility and Can-Do Spirit (2018), https:// www.dhl-in-motion.com/en/formula-1/article/the-race-behind-the-race-about-plann ing-agility-and-can-do-spirit [Accessed 26 November 2018].

Formula $1^{\circledR}$. The Worlds Fatest Logistics Race (n.d.), https://www.dhl-in-motion.com/en/formula-1/ [Accessed 26 November 2018].

Iyengar, R. (2017), The Logistics behind F1, https://medium.com/speedbox-is-typing/ the-logistics-behind-f1-7537e445de20 [Accessed 26 November 2018]. 
PCM_ADMIN (2018), Winning the Race: Behind the Scenes at Formula 1, https://logisticsmagazine. com.au/winning-the-race-behind-the-scenes-at-formula-1/ [Accessed 26 November 2018]. Young, H. (2018), "A Race Between Races" - The Demands of F1's First Ever Triple-Header, https:// edition.cnn.com/2018/07/06/motorsport/f1-triple-header-silverstone-renault-spt-intl/ index.html [Accessed 26 November 2018].

\section{Corresponding author}

Adam Wieczorek can be contacted at: adam.wieczorek@uwm.edu.pl 